\title{
Violence Against Doctors in Nepal
}

\section{Angel Magar ${ }^{1}$}

${ }^{1}$ Health Policy, Planning and Financing, London School of Hygiene and Tropical Medicine, London, UK.

Nepal is witnessing a drastic transformation from increasing awareness among consumers to political upraising in social values and perception. In this constant state of dynamic changes along with political instability, law and order is likely to be losing its grip and people seem to be taking advantage of crossing the boundaries of legal parameters.

The medical profession, once thought to be noble and respected, is losing its shine. It is being vulnerable particularly from their own patient and their relatives. Gone were the days, when doctors used to put all of their efforts to revive patients from near death state, unfortunately frequent attacks on doctors is changing the scenario in Nepal.

There are many scenarios when a patient dies then the patient's relatives start blaming for doctors' negligence over the treatment that allegation might not be true. They never seek for legal action, instead they pursue for financial compensation. ${ }^{1}$ There has been speculation that this has led to an organized crime by some opportunistic groups of people who make a deal with patients' family to share the benefit.

These days, doctors are working in a constant state of stress in the chaos of frequent news of doctors being beaten and hospitals getting vandalized. ${ }^{2}$ Most frequent method of protesting such violence against doctors is shutting down the hospitals and demanding to take action against the culprit and guarantee of their security, which is undeniably led by Nepal Medical Association (NMA).

Violence is defined as "Incidents where employees are abused, threatened, assaulted or subjected to other offensive behaviour in circumstances related to their work." ${ }^{3}$ It has long-lasting, deleterious effects on the victim's health resulting in stress, emotional shock, reduced efficiency and productivity due to physical and psychological trauma, and sometime changing or even leaving the profession.

These incidences of increasing violence against doctors might also demoralize aspiring students to choose medical profession, or increase brain drain, which might jeopardize the future of our healthcare, as doctors are still insufficient in the country.

The violence against doctors is not a new phenomenon $^{4,5}$ and even frequently reported from developed countries like the US $^{6}$ and the UK. ${ }^{7}$ Our neighbouring countries like India, ${ }^{8}$ Bangladesh, ${ }^{9}$ Pakistan $^{10}$ are also struggling with similar problem and conducting research to mitigate such issues. ${ }^{11}$

In our country, NMA has been raising this issue to the concerned authorities, political leaders, and the government, and had called for nationwide strike to draw more attention. ${ }^{12}$ Sadly, there has not been any effective measures developed by the government. ${ }^{13}$ However, Nepalese people have also realized that the matter of security is a serious issue. ${ }^{14}$

In order to protect themselves from unwanted attacks, doctors have started exaggerating patients' conditions, which is evident by a statement of a doctor in an article, "Yeah, we tell patients all the time that they might die. Doctors are getting beaten up all over the places once patients die. Who wants to take any risks?"15

There has not been any research to find out for increasing violence against doctors in Nepal. But generally, it can be summed up that the patient or patients' relatives might have been intoxicated with alcohol, attack might also have been aggravated by stress due to poor communication with doctor, financial loss, longer waiting time. On the other hand side, doctors might have been over working and burn out, resulting in poor communication with patients, lack of knowledge of self-security measures and failure to anticipate possible attacks. Likewise, hospitals might not have formulated any plans for anticipating such attacks and failure to protect their doctors in their premises, increasing privatization, and ineffective hospital management. The government is also responsible for not maintaining law and order and lack of effective policy.

As a result of increasing violence against doctors and vandalism in hospitals by patients and their relatives, the government of Nepal has passed Health Professional and Health Institutsions Protection Act, but it has not been implemented effectively in our country. Due to this, NMA is continuously raising voice and even calling for nationwide strikes demanding its effective implementation. ${ }^{16}$ Sadly, it is not that effective as compared to the act implemented in India.

Due to increasing number of attacks on doctors, Karnataka state of India has passed prevention of

Correspondence: Dr. Angel Magar, Health Policy, Planning and Financing, London School of Hygiene and Tropical Medicine, London, UK. Email: ang2el@gmail.com. 
violence and damage to property bill, 2008 to create safe environment for their work. "The rules have to be framed and a 3-year term in jail if convicted and a fine of up to Indian Rupees 50,000, and being charged with a non-cognizable offence is being planned akin to the law in Andhra Pradesh, Tamil Nadu, Punjab and Haryana". ${ }^{17}$

Similarly, "the Maharashtra Medical Services Persons and Medical Institutions (Prevention of Violence and Damages or Loss of Property) ordinance was approved by the state cabinet. The punishment and fine is as above but also with compensation for the damage (twice the value of the damages caused) and such attacks are now non-bailable, cognizable offences" ${ }^{18}$

This is high time for our government to formulate more effective health policy to address workplace violence in the health sector. Hospital should provide and promote violence free workplace and should adopt zero tolerance policy. Doctors should take all necessary precautions to reduce and eliminate risk associated with it. NMA along with other concern stakeholders need to promote training on risk of workplace violence, prevention mechanism, identification and cope with such violence. The educational institutions should conduct research on workplace violence and coordinate with media and society to contribute to the development of more effective policies and plan to combat this issue. Public should be educated to seek for legal action for professional misconduct, if any.

Violence against doctors is increasing in Nepal and will continue to surge until we take effective measures to improve healthcare in our country. It is possible, if we have violence free workplace and forthcoming new constitution addresses this issue.

\section{REFERENCES:}

1. Dahal K. Angry relatives attack doctors and hospitals in Nepal. BMJ. 2008;337:1946.

2. Sitaula S, Magar A. Medical practice in the peripheral health centers in Nepal. J Nepal Health Res Counc. $2011 ; 9(2): 198-200$.

3. di Martino V. Relationship between work stress and workplace violence in the health sector [Online]. Geneva: ILO/ICN/WHO/PSI; 2003 [cited 2013 Nov 02]. Available from: http://www.who.int/violence_injury_prevention/ violence/interpersonal/WVstresspaper.pdf.

4. McCain JR. Doctors Attack Number One Epidemic. Journal of the Medical Association of Georgia. 1963;52:410.

5. How the tide of violence has hit doctors. Medical times. 1973;101(9):56-64.

6. Kowalenko T, Walters BL, Khare RK, Compton S, Michigan College of Emergency Physicians Workplace Violence Task F. Workplace violence: a survey of emergency physicians in the state of Michigan. Ann Emerg Med. $2005 ; 46(2): 142-7$.

7. Vanderslott J. A study of incidents of violence towards staff by patients in an NHS Trust hospital. J Psychiatr Ment Health Nurs. 1998;5(4):291-8.

8. Madhok P. Violence Against Doctors. Bombay Hospital Journal. 2009;51(2):301-2.

9. Khan M, Ahasan H, Mahbub M, Alam M, Miah M, Gupta R. Violence against doctors. J Med. 2010;11(2):167-9.

10. Khawaja A, Irfan H. Violence against doctors in government hospitals and the role of media. J Pak Med Assoc. 2011;61(11):1163.

11. Mirza NM, Amjad Al, Bhatti AB, tuz Zahra Mirza F, Shaikh KS, Kiani J, et al. Violence and abuse faced by junior physicians in the emergency department from patients and their caretakers: a nationwide study from Pakistan. The Journal of emergency medicine. 2012;42(6):727-33.

12. Republica. Docs to halt all but emergency service. Republica. 2009.

13. NMA News, 2009. J Nepal Med Assoc. 2009;48(176):A-D.

14. Dhakal P. Unbecoming strike of doctors. Republica. 2009.

15. Nepal I. Diagnosis of death [Politically Cracked]. Kathmandu, Nepal: Himal Media Private Limited; 2011 Jan 14 [cited 2013 Oct 10]. Available from: http://nepalitimes.com/news.php?id=17840 - .U9eeyoBdVcl.

16. Service HN. NMA urges safety, security for health workers. The Himalayan Times. 2013.

17. Animesh J. Karnataka Medicare Service Persons and Medicare Service Institutions Bill. Natl Med J India. $2009 ; 22(2): 104$.

18. Srinivasan S. Violence on doctors is an offence in Maharashtra. Natl Med J India. 2009;22(2):104-5. 